\title{
Aproximaciones a la escenografía en prospectiva de la producción de eventos
}

Daniel Maya Tabares; Kamila Oquendo Botero;

Laura Sofia Hernández Giraldo; Valentina Molina Restrepo;

Yessenia Alzate Valderrama*

DOI: https://doi.org/ 10.33571/revinterseccion.v2n4a4

\section{Resumen}

La escenografía implica a la decoración, el sonido, la iluminación y la puesta en escena. En la producción de un evento, ésta es un aspecto importe en tanto compromete la puesta en escena de la idea creativa y los contenidos. En esta aproximación se presentan algunos aspectos de la historia de la escenografía y de los renovadores de ésta, entre los que encuentran: Bertolt Brecht, Pablo Picasso, Adolphe Appia, Gordon Craig.

Palabras clave: Escenografía; eventos; decoración;

entretenimiento; diseño escénico.

Recibido. Agosto 12, $2020 \quad$ Aceptado. Agosto 17, 2020

\footnotetext{
*Estudiantes del curso seminario de investigación aplicada de la Tecnología en Producción de Eventos del Politécnico Colombiano Jaime Isaza Cadavid, coordinado por la profesora Mónica Valle; email: mmvalle@elpoli.edu.co ; email estudiantes:daniel_maya35182@elpoli.edu.co ; kamila_oquendo35182@elpoli.edu. co ; laura_hernandez35182@elpoli.edu.co ; valentina_molina35182@elpoli.edu.co ; yessenia_alzate35182@elpoli.edu.co
} 


\section{Approaches to scenography in the prospective of event production}

Daniel Maya Tabares; Kamila Oquendo Botero;

Laura Sofia Hernandez Giraldo; Valentina Molina Restrepo;

Yessenia Alzate Valderrama*

DOI: https://doi.org/ 10.33571/revinterseccion.v2n4a4

\section{Abstract}

Scenography involves decoration, sound, lighting, and staging. In the production of an event this is an important aspect since it implies the staging of the creative idea and the contents. In this approach some aspects of the history of scenography and its renovators are introduced, among which are: Bertolt Brecht, Pablo Picasso, Adolphe Appia, Gordon Craig.

Keywords: Scenography; events; decoration; entertainment; scenic design.

Received. August 12, 2020

Accepted. August 17, 2020

\footnotetext{
*Students of the applied research seminar course of the Technology in Event Production of Politécnico Colombiano Jaime Isaza Cadavid, coordinated by professor Mónica Valle; email: mmvalle@elpoli.edu.co ; email students: daniel_maya35182@elpoli. edu.co; kamila_oquendo35182@elpoli.edu.co; laura_hernandez35182@elpoli.edu. co; laura_hernandez35182@elpoli.edu.co; valentina_molina35182@elpoli.edu.co ; yessenia_alzate35182@elpoli.edu.co
} 


\section{Abordagens à cenografia em prospectiva de produção de eventos}

Daniel Maya Tabares; Kamila Oquendo Botero;

Laura Sofia Hernández Giraldo; Valentina Molina Restrepo;

Yessenia Alzate Valderrama*

DOI: https://doi.org/ 10.33571/revinterseccion.v2n4a4

\section{Resumo}

A cenografia envolve decoração, o som, a iluminação e a cenografia envolve decoração, som, iluminação e encenação. Na produção de um evento, este é um aspecto importante, pois implica a encenação da idéia criativa e dos conteúdos. Nesta abordagem, são apresentados alguns aspectos da história da cenografia e de seus renovadores, entre eles: Bertolt Brecht, Pablo Picasso, Adolphe Appia, Gordon Craig.

Palavras chave: Cenografia; eventos; decoração; entretenimento; desenho cênico.

*Estudantes do curso de seminário de pesquisa aplicada da Tecnologia em

Produção de Eventos do Politécnico Colombiano Jaime Isaza Cadavid, coordenado pela professora Mónica Valle; email: mmvalle@elpoli.edu.co ; email estudiantes: daniel_maya35182@elpoli.edu.co ; kamila_oquendo35182@elpoli.edu.co ; laura_ hernandez35182@elpoli.edu.co ; laura_hernandez35182@elpoli.edu.co ; valentina_ 
rededor del mundo se cuenta con programas formativos en torno a la escenografía además de congresos y publicaciones que dan cuenta de una

disciplina que cada vez cobra más relevancia para aplicarse en otras disciplinas y campos profesionales como la producción de eventos por su capacidad de crear expresiones y significados nuevos [1]

Este documento está hecho con el fin de promover y visualizar esta profesión, pero también por medio de este trabajo se quiere mostrar cómo han cambiado los diseños escenográficos en los diferentes momentos de la historia.

\section{Breve historia de la escenografía}

Se sabe que las primeras escenografías provinieron de Grecia, cuando en su época clásica sucedieron representaciones teatrales públicas, dedicadas al dios Dionisos. Fue así como surgió el teatro griego en las vertientes de tragedia y comedia. Tespis, fue un dramaturgo griego, ganador del primer concurso de tragedias. Durante aquella época las obras solamente tenían un único actor. Por su parte en la antigua Roma, el teatro nació a partir de los festivales celebrados en honor a los dioses, se representaba la vida de éstos. A partir del Siglo V, A.C. se empezaron a construir escenarios que pudieran contener a una orquesta; una puesta en escena, un coro y a los actores. Con el fin de mejorar el sonido los romanos ubicaron la orquesta en semicírculo alrededor del escenario y dividieron las gradas en 3 partes (políticos, pueblo, mujeres), dando origen a lo que son los modernos espectáculos. Esta idea provenía de los griegos.

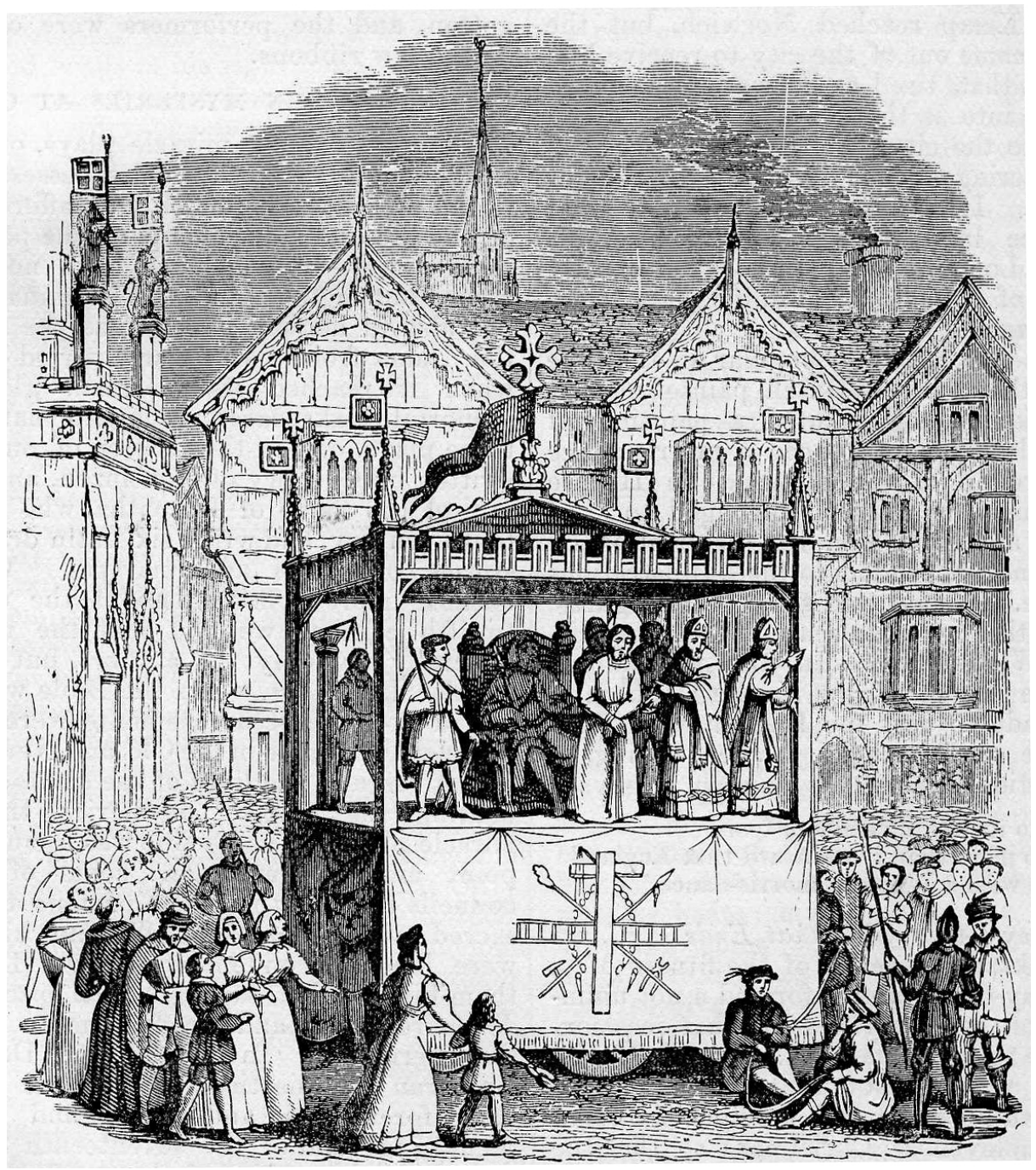


En la Edad Media, se presentaron variaciones de las escenografías que han tenido influencia en la técnica escénica, puede citarse la decoración circular de las célebres carretasescenas del medioevo, sobre la cual se presentaban ante los espectadores los más pintorescos lugares propios de los diversos episodios de los misterios o los juegos escénicos de la época. Ese hallazgo es precursor de los escenarios giratorios modernos. Otra característica de la época era la escena simultánea, en donde se sucedían los lugares de acción del espectáculo

El principio de la escenografía proviene de un decorado que se utilizó en toda la edad media, éstas eran utilizadas para representar obras religiosas y profanas. En el Renacimiento, cuando no era posible mostrar en estos compartimentos lugares como selvas o campos de batalla, un actor se encargaba de "explicar" la escenografía.

En la baja Edad Media, en los teatros ingleses, la disposición de los teatros procede de los patios de las ventas. Fueron más frecuentes las construcciones de forma circular que las cuadradas, como por ejemplo el teatro del Globo, en el que se representaban las obras de Shakespeare. Como escenografía, se empleaban tapices para cerrar el fondo del escenario y se solía cubrir el tablado con una estera. Sobre la escena había una especie de balcón que se utilizaba como palco de orquesta, pero en el que también se desarrollaban escenas, además de esto la escenografía se limitaba a elementos móviles como pequeños elementos de utilería.

Desde el Renacimiento hasta bien entrado el Siglo XIX la escenografía italiana ha nutrido al teatro y ha sido el ejemplo para los escenógrafos. En el año de 1428, en Roma se hallaron comedias desconocidas de Plauto y al mismo tiempo se desarrollaron obras teatrales que se representaban en las cortes. El escenario para los nuevos espectáculos se podía representar en cualquier lugar, en jardines o salones de palacios. La escenografía sufrió una gran transformación gracias al arte de la perspectiva. Surgió la necesidad de ampliar el escenario, dando a su fondo una disposición artística.

En el Renacimiento se construyó el Olimpo de Vicenza, 1585, obra del arquitecto Andrea 


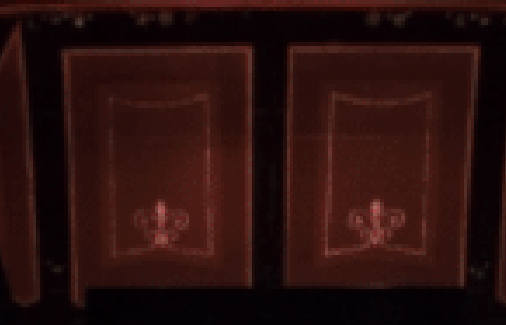

Palladiom, con un escenario de madera; síntesis grandiosa de la estética arquitectural de la escenografía de la época que consistió en que la decoración estuviera dispuesta según los cánones artísticos de la perspectiva lineal. Columnas corintias, bajorrelieves, estatuas y cornisamientos adornaban la fachada escénica. En medio se abre la puerta mayor, o puerta real, según Vitrubio, porque solo los actores principales aparecían por ella, a manera del teatro griego. El humanismo característico de la cultura y el arte de la época hizo variar la temáticas de las obras, aparece la comedia del arte, con sus exigencias escenográficas especiales.

A finales del XVI, se transforma la decoración fija en móvil, y la escena tuvo una época majestuosa y brillante tanto en Italia como en Francia. El procedimiento de los telari (primas triangulares) fue sustituido por la escenografía de los bastidores utilizada por primera vez en el Teatro Farnesio. El uso de los bastidores se propagó por toda Italia y se hizo popular en Europa por la rapidez y la facilidad con que verificaban las mutaciones. Giovanni Battista Aleotti construyó en 1618 el Teatro Farnesio con el graderío en forma de herradura. Posteriormente el arquitecto Fabrizio Garini Motta, de Mantua diseñó el teatro de palcos superpuestos y llegó a la forma que ha perdurado hasta nuestros días.

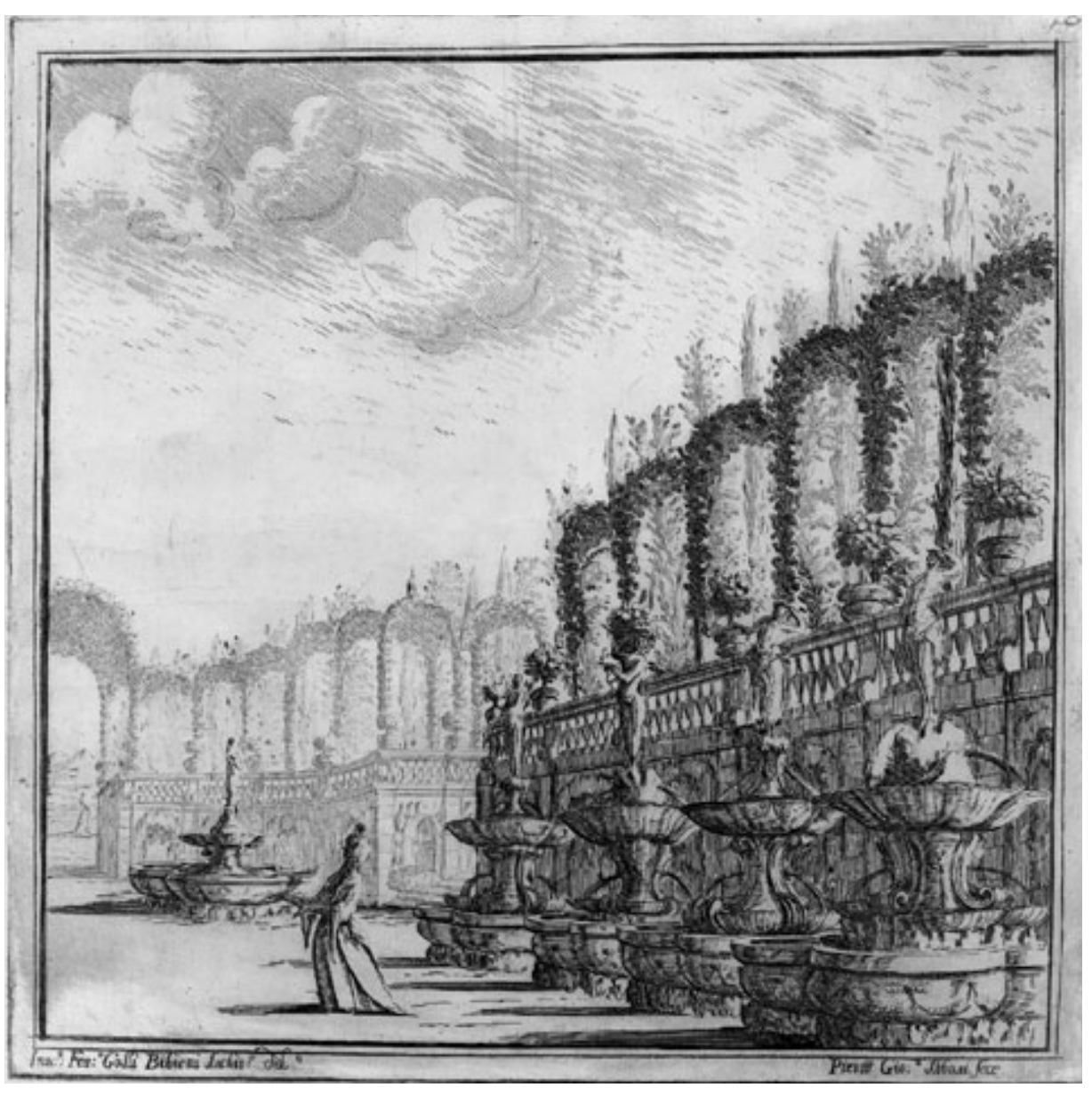

Parque en una escenografía de Galli Bibiena 
En el siglo XVII el teatro se desarrolló en el espacio público, calles y plazas en donde se celebran representaciones religiosas. En Italia florecieron arquitectos y escenógrafos como Serlio, Buontalenti, Baccio del Bianco, Burnacini, Tacca, Perruchetti, Nerona, y Torelli.

Los Galli Bibiena (1659-1743) hicieron el hallazgo de conseguir y lanzar la nueva perspectiva pictórica, de forma que la arquitectura no solo se observaba de frente, sino que ofrecía aspectos desde diferentes ángulos. De esta manera surge un nuevo tipo de escenógrafo pintor. La iluminación escénica también debía ayudaren las conquistas de la escenografía. Las candilejas fueron una innovación del siglo XVII. La ópera participó en su desarrollo, pues era un género que reclamaba gran presentación y para ello era necesario que los arquitectos, que eran a su vez constructores y pintores, fueran dando paso a los escenógrafos, es decir, a los especializados en el arte de crear climas escénicos.

Francia debía intervenir para consolidar las nuevas conquistas. León Moussinac, experto en esta materia, dice al respecto: El sistema moderno de decorados de tela pintada, es decir, de decoraciones sucesivas en reemplazo de decorados simultáneos fue creado por Mahelot y Laurent, quienes trabajaron para Molière. De esta época es Giovanni Niccolo Servandoni, gran escenógrafo que montó los mejores espectáculos de ópera. Fue en ese admirable siglo XVII cuando nació la decoración teatral propiamente dicha, en la que puso entonces el artista su originalidad y el aporte de su personalidad. Por esta época la escenografía buscaba la verdad. Los escenógrafos Albany, Moenck, Alaux y Daguerre rivalizan en ingeniosidad. El gas, que acababa de hacer su aparición permitía sorprendentes iluminaciones.

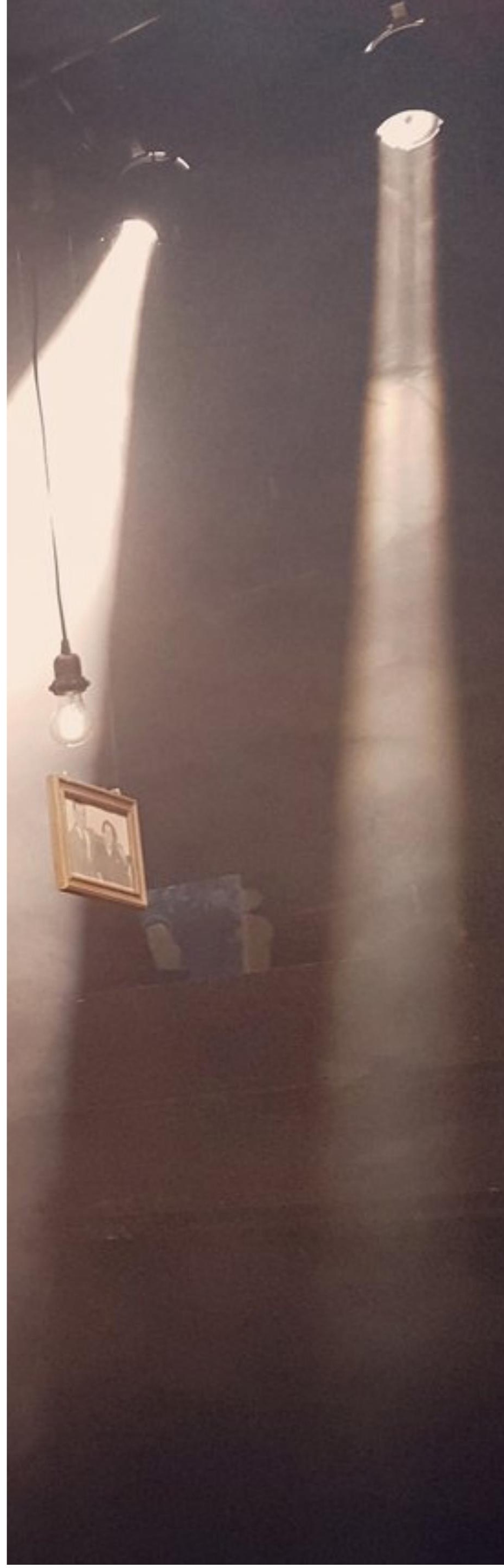




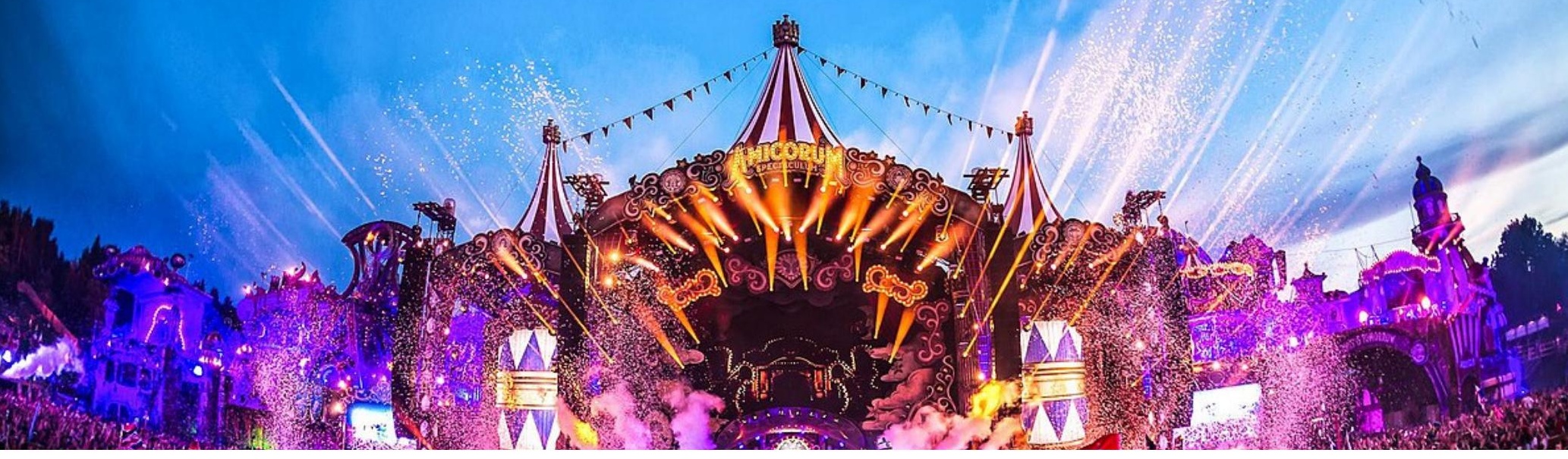

En el Siglo XIX el romanticismo abandonó la realidad para entregarse a lo peculiar. La iluminación permitió el paso de la escenografía objetiva a la escenografía más emotiva. Tras la exuberancia demostrada en los siglos XVII y XVIII se cayó en la banalidad y en el verismo de mal gusto. En esta época la invención corresponde a los escenógrafos y tramoyistas como los Camus, Brabant, Varnout, Godin y Colombier. El simbolismo concluyó que la palabra podía suplir todo, con lo cual la escenografía pasó a un segundo plano, así la escenografía pasó a ser decorativismo. A finales de este siglo surgieron algunos esfuerzos en contra del convencionalismo existente.

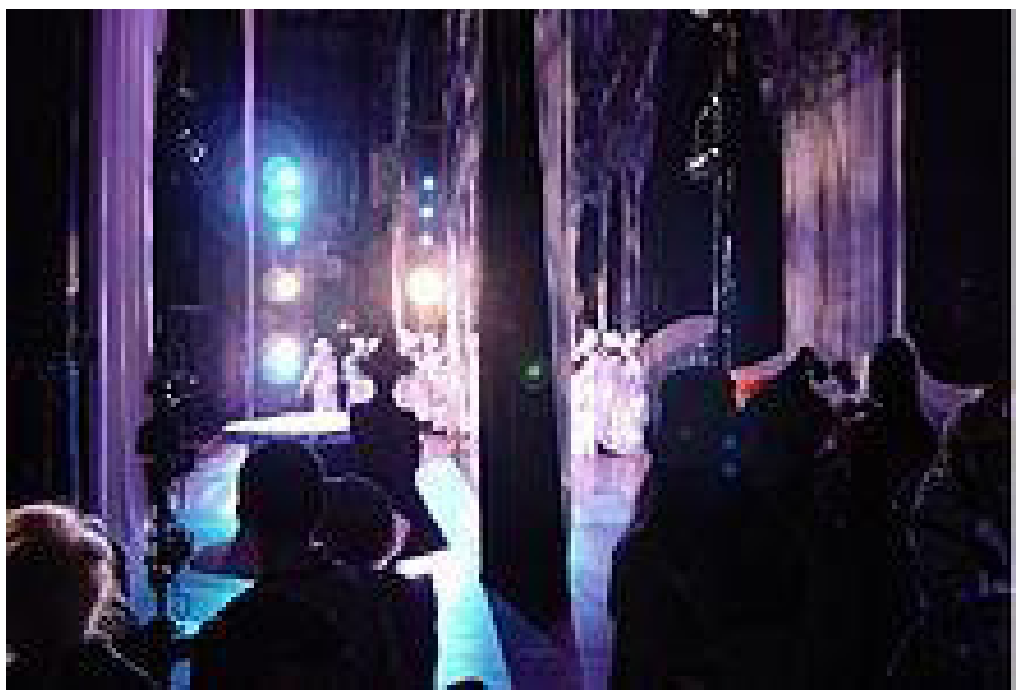

Representación vista entre bastidores
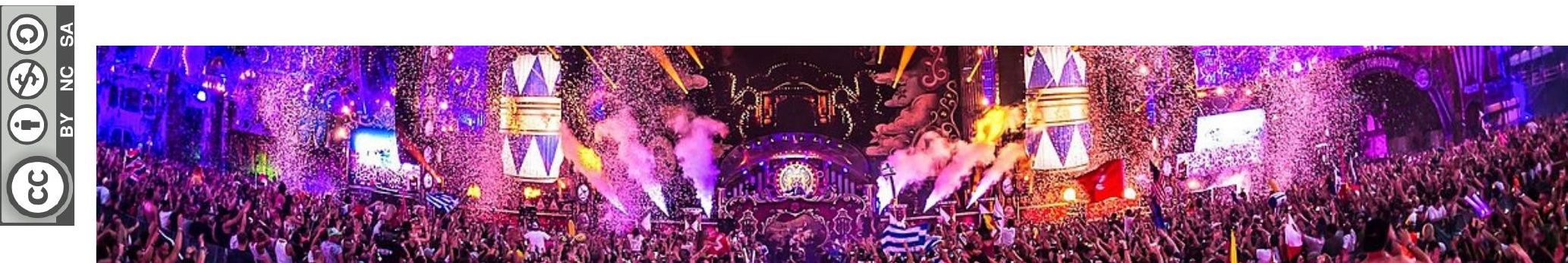
En el Siglo XX, todo contribuye a la formación de las nuevas tendencias escenográficas para que los problemas dejaran de ser de orden exterior. Las habitaciones se cerraron con paredes y plafones, porque el naturalismo exigía una realidad ambiente que no se consigue con bastidores y telones de fondo. El gas había sustituido la iluminación a vela y aceite.

En 1887, el Teatro Libre de André Antoine, en París, buscaba la verdad en el decorado, describe la cuarta pared que cierra el espacio: los actores pueden reproducir también para crear la ilusión de un sistema cerrado, y el espectador tiene la impresión de "inmersión" en la vida cotidiana de la historia, se convierte en voyeur frente a la representación. En este momento se reproducen casas enteras en el escenario, se incluyen muebles que dan la ilusión de realidad.

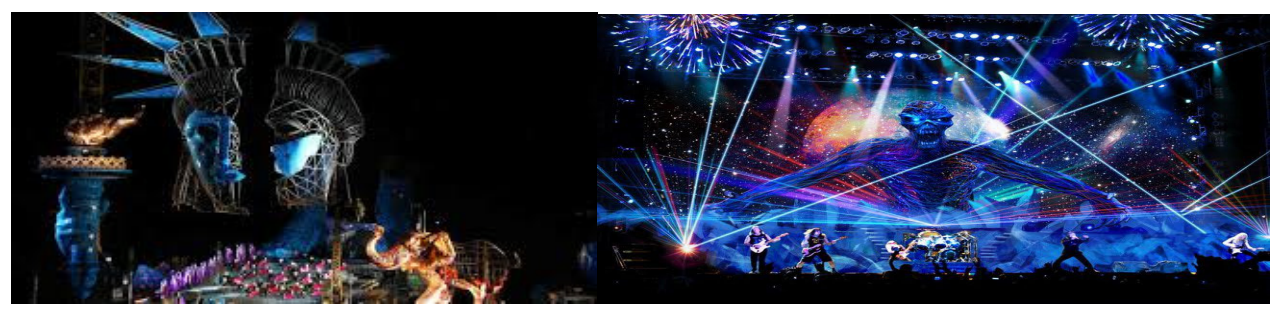

En el Siglo XXI, se diseñan espacios escénicos para artes en vivo (teatro, música, danza y ópera), así como para exposiciones, eventos y televisión. Se concibe la interrelación entre público, intérpretes y espacio como clave en la percepción de la creación artística. Las escenografías son intervenciones espaciales que interrogan la mirada del público, ofrecen puntos de vista abiertos y no jerárquicos.

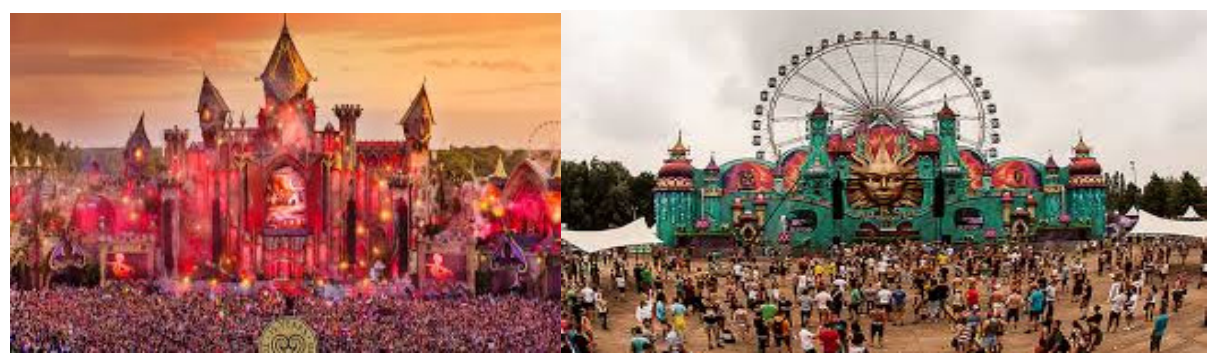

Se utilizan espacios no convencionales que permitan que la disposición de público e intérpretes sea variable y no basada en la frontalidad. Se destaca el papel activo del público en la recepción de la creación en vivo y el espacio adquiere un valor dramatúrgico. Se concede gran importancia a la luz como un agente fundamental en la cualificación espacial.

A mediados de noviembre del año 2013, se realizó en Tandil (Prov. De Buenos Aires, Argentina) el Primer Congreso Nacional de Escenografía, el cual contó con la presencia de escenógrafos reconocidos, profesionales ligados al diseño escénico. Se repensó la formación, la profesionalización y los desafíos para esta disciplina. Participaron en el evento Héctor Calmet, Carlos Di Pasquo y Norberto Laino, quienes plantearon nuevos y viejos paradigmas del diseño escénico.

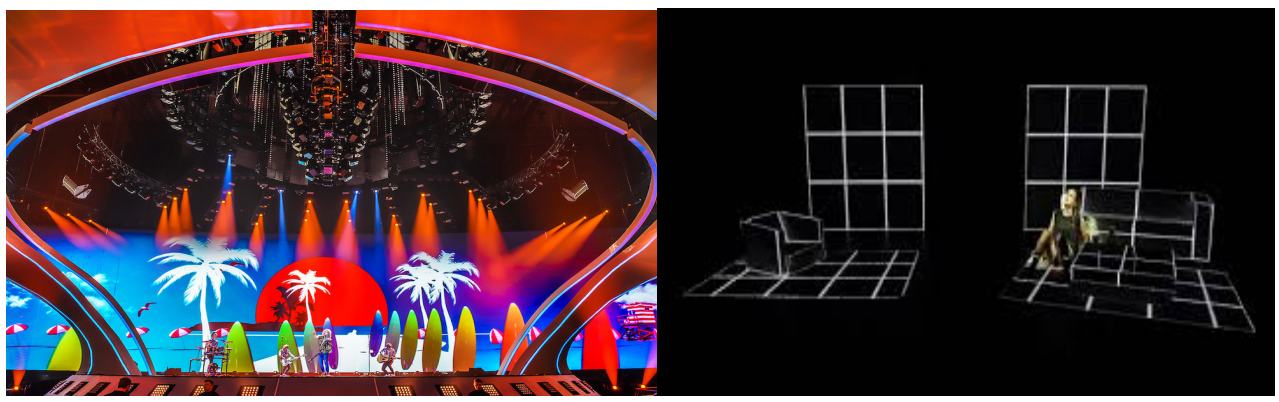

Danny Popkin, experto en escenarios virtuales de la BBC, en año 2000 motiva al uso de escenarios virtuales en la televisión. "La escenografía virtual es una excelente herramienta para ahorrar costes de producción y además ofrece ventajas en la realización de noticias, 
programas infantiles, espacios de televenta 0 en programas especiales de elecciones. Sin embargo, es necesario que la escenografía virtual ofrezca más verosimilitud y simplicidad en sus escenarios, una presentación de la información en tiempo real más atractiva y aportaciones creativas para formatos de entretenimiento" (Galán y Fernández, 2011)

\section{Renovadores de la escenografía}

Gordon Craig. Nació en Inglaterra, un genio del teatro, que luchaba por dar un estilo al escenario para que no se confundiera con la realidad, para él el escenógrafo deberá escoger el color y la pieza, el motivo artístico alrededor del cual agrupará los demás objetos. Para Gordon Craig la palabra es el lugar de la mentira, lo literario ocupa un lugar secundario respecto a lo visual y lo rítmico.

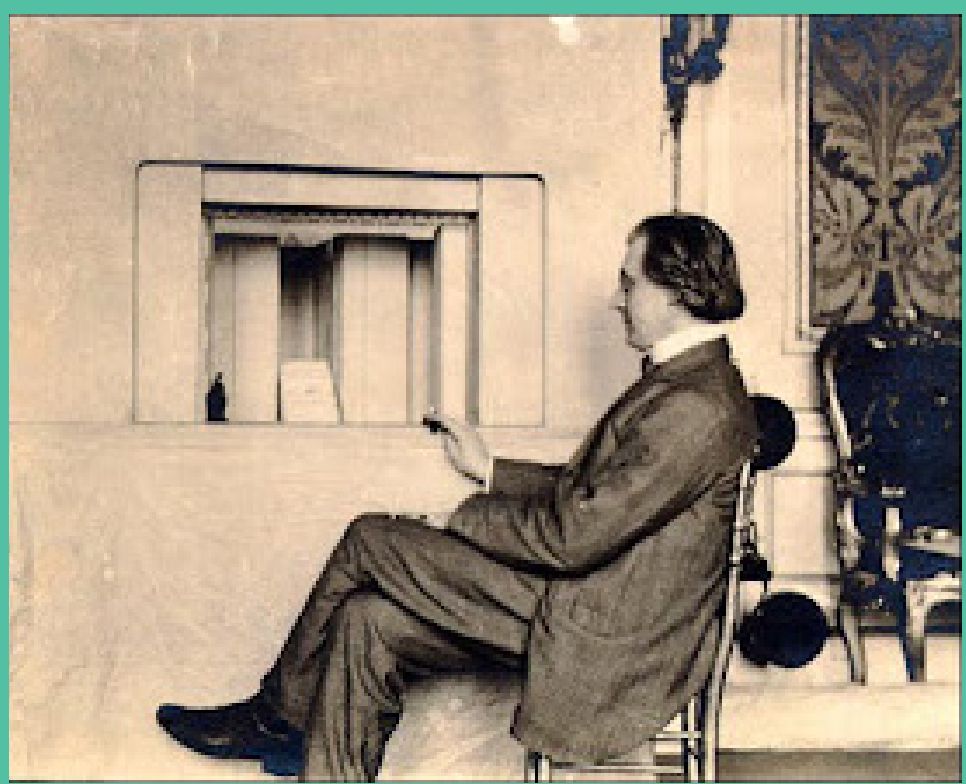

Loie Fuller. Fue una bailarina estadounidense pionera en la utilización de la iluminación. Alcanzó un gran éxito en Les Folies Bergère con sus danzas basadas en el aprovechamiento del efecto de la luz coloreada sobre sus trajes vaporosos, para reproducir sensaciones del mundo natural. Para ella los elementos que componen el espectáculo escénico son en este orden: luz, color, movimiento y música.

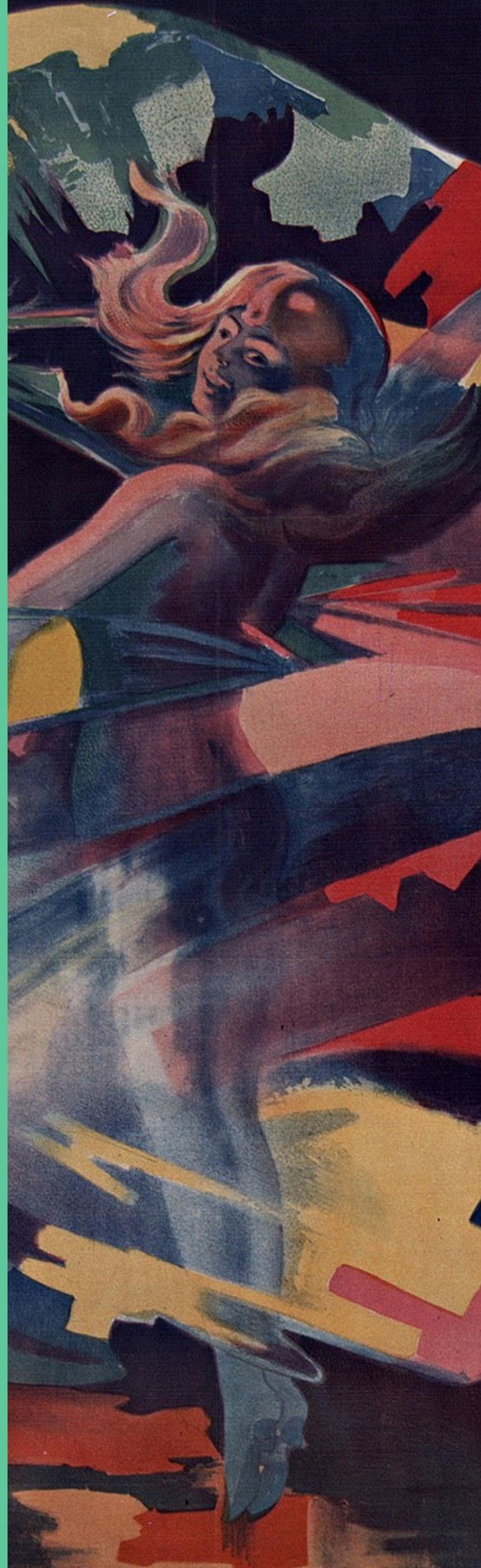




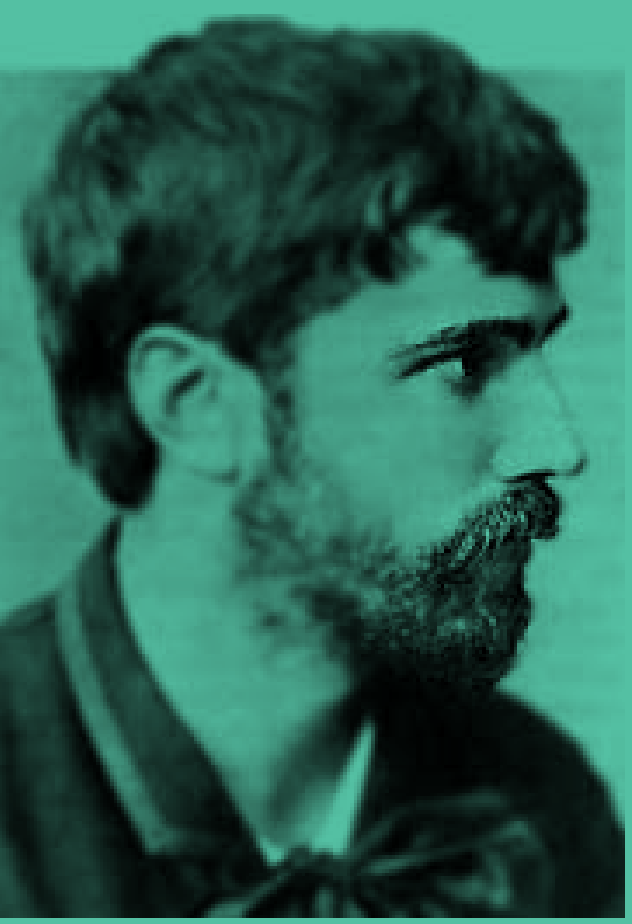

Adolphe Appia. Nació en Suiza, músico de formación, para él los movimientos del actor y sus pasos deben ser medidos por la música. Lo escénico deja de ser el lugar donde se dota de acción física a un conflicto dialogado para convertirse en espacio para la materialización de una acción y un conflicto precipitados originalmente en música. Su reflexión sobre lo escenográfico parte de su desprecio hacia los decorados ilustrativos, piensa los elementos escénicos como signos en sí mismos y no como soportes de imágenes convencionales. Para Appia la luz será la responsable de realizar escénicamente la melodía infinita wagneriana.

George Fuchs que ratifica la necesidad del decorado plástico, su hallazgo es la "escena en relieve". Todo estaba preparado para recoger las grandes ventajas que aportaba la electricidad. La transformación había llegado. Existía de hecho una luz que podía exaltar el color, proyectar sombras, crear atmósferas no conocidas hasta entonces y dar relieve a lo corpóreo en la escena.

Pablo Picasso hizo decorados para el ballet de Manuel de Falla, El Sombrero de Tres Picos, y Jacques Copeau, así como Gaston Baty, Lovis Jouvet y Charles Dullin acogieron fervorosamente las más audaces tendencias. Antón Giulio Bragaglia y Enrico Prampolini en Italia crearon escenografías dentro de directivas muy personales.

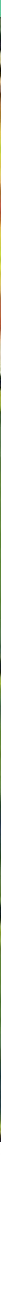




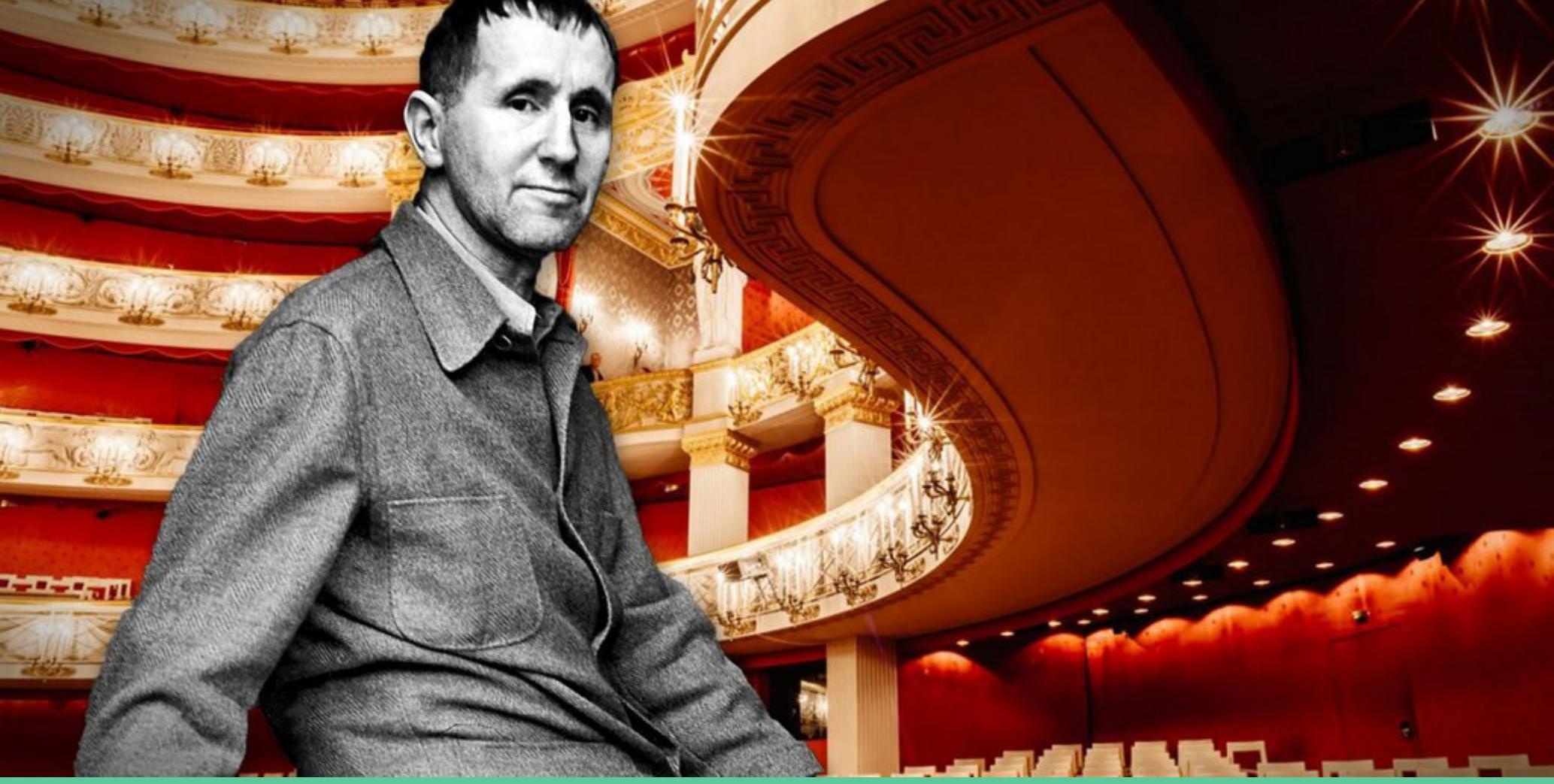

Bertolt Brecht. En su actividad como director de escena desarrolló una teoría escenográfica, - la escenografía es la ciencia de hallar un espacio que convenga a cada texto teatral-. A partir de Brecht se consideró decadente dar demasiada importancia a la escenografía y a la espectacularidad en la puesta en escena. Para Brecht, la realidad debe poder reconocerse en el teatro, su esencia debe transparentarse. Lo que ocurre en el escenario debe poder reconocerse como algo que se ha hecho (en el sentido de no algo espontáneo o natural). Y es justamente este hacer notar la diferencia entre la realidad del teatro, por una parte y la realidad que el teatro trata de reflejar, por otra, que es un acto de enajenación. Y tal como la técnica de actuación, también la escenografía debe transparentar sus medios. Por ejemplo, las fuentes de luz deben poder verse. Por otra parte, para Brecht era muy importante que todo lo que estuviese sobre el escenario tuviera directa relación con las escenas y su devenir. Su «teatro épico» no admitía que la escenografía contemplara objetos superfluos o no directamente relacionados con el guion.

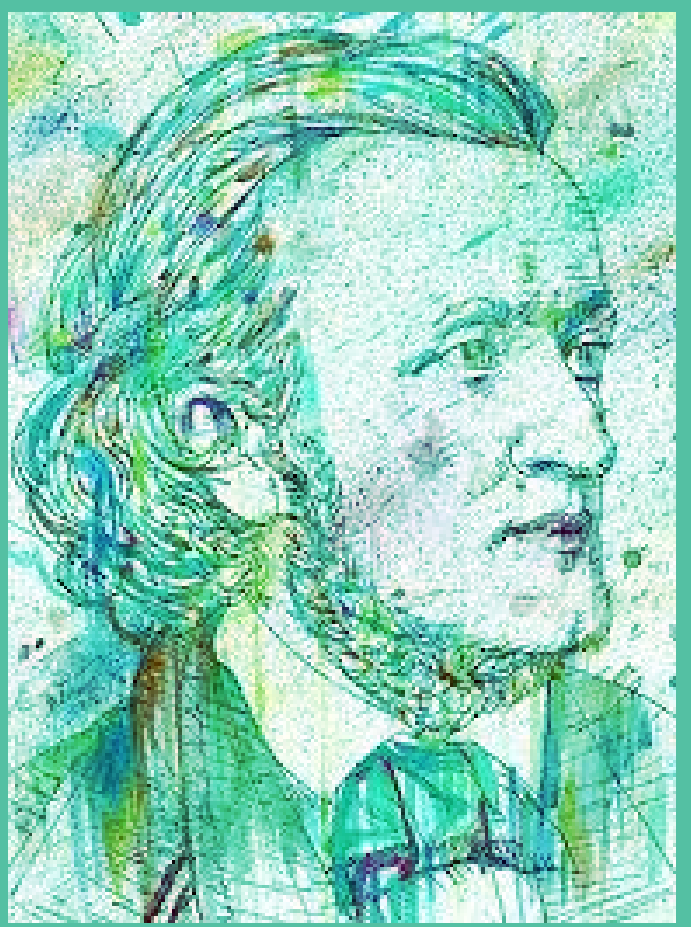

Richard Wagner. Establece la hibridación de lo escénico, apresar en una obra en la que intervienen los diversos lenguajes artísticos el flujo inagotable de lo real, el movimiento infinito del espíritu. La obra de arte total, donde la disipación de los límites coincida con el propósito de una obra de arte que sea extensión de lo natural y elaborada según un modelo orgánico, en el cual toda regla es flexible y toda división permeable. En la obra de arte total el drama actúa como elemento estructural y la música como elemento de mediación y enlace. La música y la plástica servirían de punto de partida y de ellas crecería el drama, como unión de la música, la palabra y la imagen. Aunque Wagner no potenció el diálogo entre la pintura y la música contribuyó a potenciar éste en el siglo XX a través de Adolphe Appia. 


\section{A manera de conclusión}

En el Siglo XXI, se diseñan espacios escénicos para artes en vivo (teatro, música, danza y ópera), así como para exposiciones, eventos y televisión. Se concibe la interrelación entre público, intérpretes y espacio como clave en la percepción de la creación artística. Las escenografías son intervenciones espaciales que interrogan la mirada del público, ofrecen puntos de vista abiertos y no jerárquicos.

Un escenógrafo es un especialista en el arte de crear climas escénicos. Es importante conocer los orígenes las escenografías para así entender de dónde surgen estos diseños de espacios, y a partir de esto, crear diseños y conceptos adecuado a los intereses y necesidades de los eventos que se produzcan. Entre los renovadores de la escenografía se encuentran: Bertolt Brecht, Pablo Picasso, Adolphe Appia, Gordon Craig.

Se debe tener en cuenta el protagonismo e impacto que causa las escenografías en los participantes de un evento, por lo que se debe fortalece este tipo de disciplina. Es importante empezar a crear algo nuevo para aprovechar el gran potencial que se tiene en la producción de eventos.

La constante evolución de los eventos ha generado una revolución en cuanto a su diseño y escenografía, al pasar de procesos analógicos a digitales e implementando tecnologías que hacen más fácil la adaptación de los espacios a las temáticas queridas, mejorando la experiencia de los asistentes y de los mismos organizadores de eventos.

\section{Bibliografía}

Aguilar García, María del Mar (2010) . La escenografía según el espectáculo a que va destinada. Activarte. Revista independiente de arte. teoría de las artes, pedagogía, nuevas tecnologías. Disponible en: file:///C:/Users/Usuario/Downloads/Dialnet-LaEscenografiaSegunE IEspectaculoAQueVaDestinada-4046369.pdf

Castellano, Paula: «La Escenografía como medio Relacional \#PQ19) en Revista Godot, 7-72019. Disponible en: http://www.revistagodot.com/la-escenografia-como-medio-relacionalpq19/

Erviti, Claudio (2012)Proyecto y espacio público. Escenografías expresionistas para el Festival Cinematográfico de Mar del Plata. Jorge Sabaté, 1954. I+A Investigación + Acción. Año 15 I $N^{\circ}$ 14. Disponible en:

file:///C:/Users/Usuario/Downloads/24-Texto\%20del\%20art\%C3\%ADculo-94-1-10-20160331.pdf

Fuente Lafuente, Carlos (2005). Manual práctico para la organización de eventos. Ediciones Protocolo - España.

Galán Cubillo, Esteban y Fernández Fernández, César (2011). La escenografía virtual en la retransmisión de grandes eventos. Revista latina de comunicación social (2011), no. 66, p. 6378. http://dx.doi.org/10.4185/RLCS-66-2011-924-063-078

Lucena-Muñoz, Eufrasio (2019). La Cuatrienal de Praga (pq'19): Reflexiones sobre una plural participación desde los comisariados. Disponible en: file:///C:/Users/Usuario/Downloads/489Texto\%20del\%20art\%C3\%ADculo-2484-1-10-20210120.pdf

Lucena Muñoz, Eufrasio (2019): La Cuatrienal de Escenografía de Praga (PQ'19): imaginación, transformación y memoria. ADETeatro. Revista de la Asociación de Directores de Escena de España. № 176.

Valle, M., y Moreno, G. (2015). Tecnología en Organización de Eventos del Politécnico Colombiano Jaime Isaza Cadavid en el contexto de Medellín como ciudad de eventos. Revista Intersección. Eventos, Turismo, gastronomía Y Moda, 46 -54. Recuperado a partir de https:// revistas.elpoli.edu.co/index.php/int/article/view/228 
Villanueva Llauradó, Paula (2018). Metodología Análisis-Proyecto para diseño y escenografía de actos y eventos. Disponible en : https://dialnet.unirioja.es/servlet/articulo? codigo=7372023

\section{Notas}

[1] La escenografía en la organización de eventos. En CEUPE. Escuela de Negocios de marcado carácter internacional con presencia en más de 30 países, líder en la Formación Online de Postgrado. Disponible en: https://www.ceupe.com/blog/escenografia-organizacioneventos.html

\section{Para citar este artículo}

Maya Tabares, Daniel; Oquendo Botero, Kamila; Hernández Giraldo, Laura Sofía \& Otros.

(2021). Aproximaciones a la escenografía en prospectiva de la producción de eventos. Revista Intersección: Eventos, turismo, moda y gastronomía. Vol. 2 Núm. 4. Pp: 49-62; https://doi.org/ 10.33571/revinterseccion.v2n4a4

OJS: hittps://revistas.elpoli.edu.co/index, pho/int/issue/archive. Link: hittps://www.politecnicojic.edu.co/index.php/revista-interseccion. 